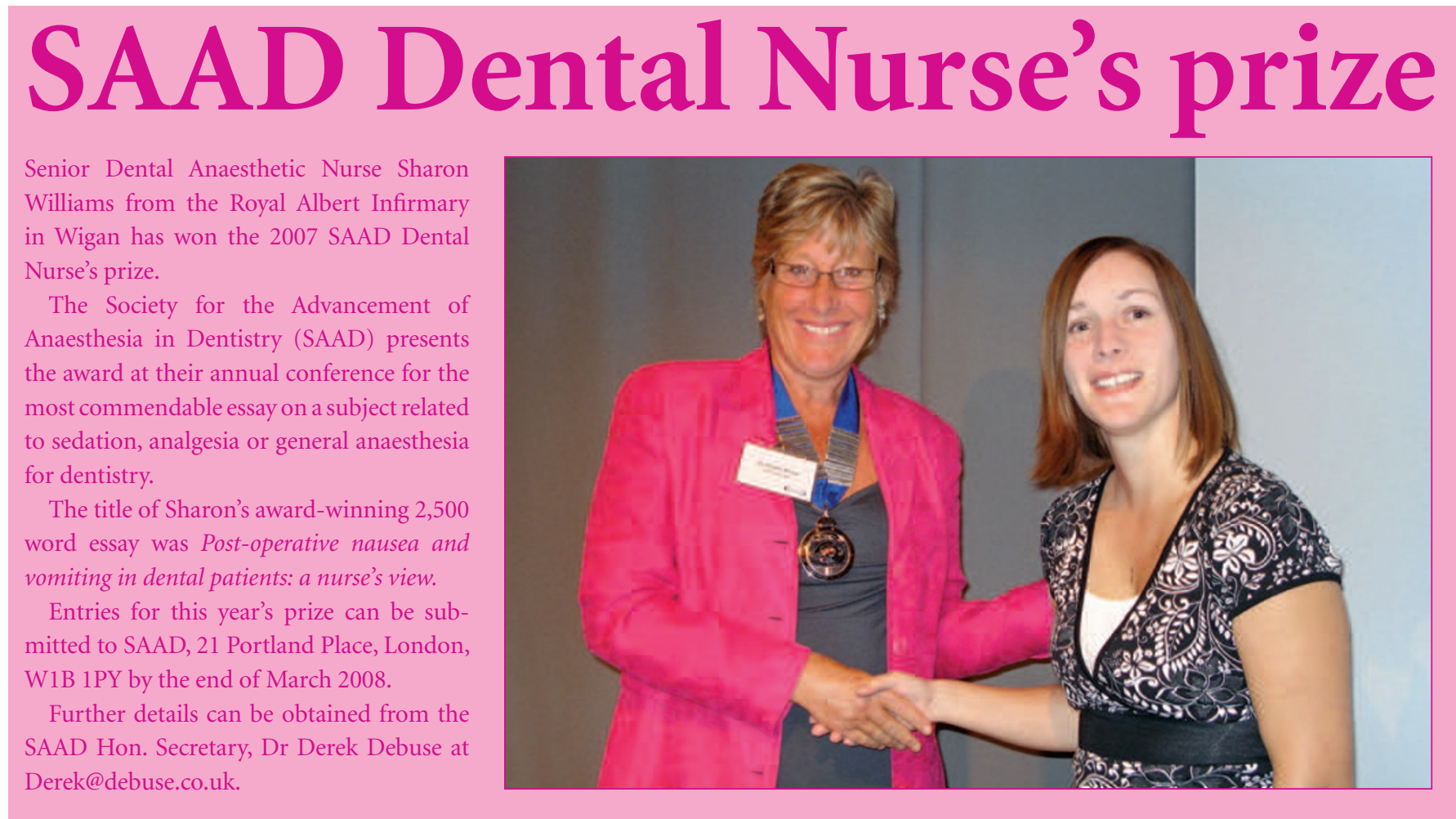

\title{
Tony is top technician
}

Tony Griffin was presented with the inaugural Dental Technologists Association Award in recognition of his outstanding contribution to dental technology over many years. $\mathrm{He}$ received the award at the BDA Honours and Awards Dinner held at the Millennium Hotel in London.

Tony is a past Chairman of the Dental Technicians Education and Training Advisory Board and former President of the Dental

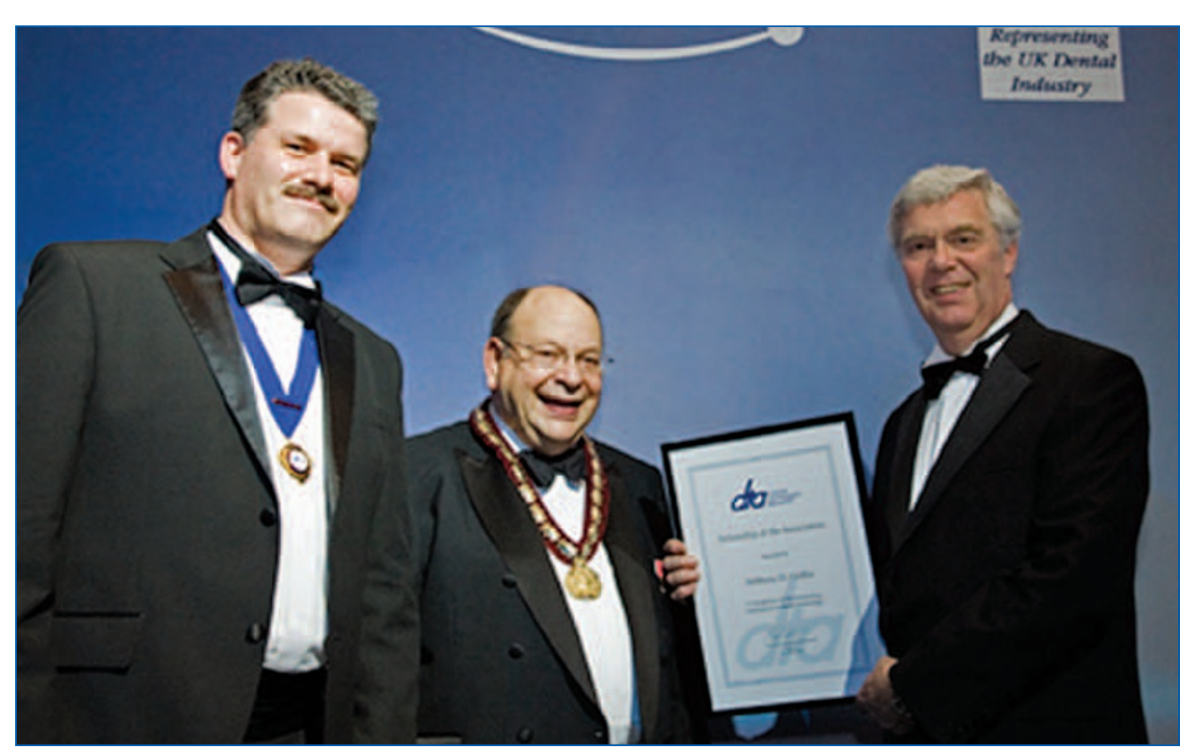

(From left to right) Paul Mallett, current DTA President, Josef Rich, BDA President, and Tony Griffin

Technologists Association (DTA).

Qualifying as a dental technician in 1969, he has since gained an honours degree in business studies, a certificate in education and a clinical dental technician's certificate. He has managed a commercial dental lab in Birmingham and taught in two colleges. He was also instrumental in creating the first ever Foundation Degree programme for dental technicians.
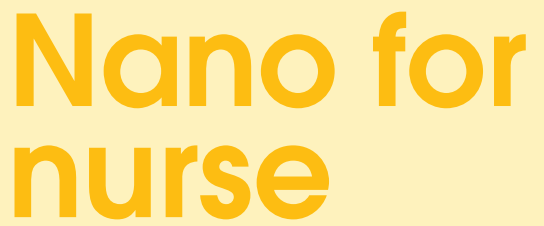

Dental nurse Jan Whiting, whose career as a dental nurse spans almost four decades, won an iPod nano in the BDTA prize draw held at the BADN conference in November.

Jan was over the moon and said: 'The BDTA's generosity [will make] my journey to work in London from my home in Eastbourne very tolerable.'

Shortly before winning the iPod Jan had received her scroll for being elected a fellow of the British Association of Dental Nurses (BADN).

Jan has worked in the school dental service, a special needs mobile unit, general practice, community dentistry and in no fewer than four hospitals. In the last 20 years she has worked at Guy's and St Thomas' Foundation Trust and with cleft lip and palate children in the Evelina Children's Hospital.

'Jan is a worthy winner of the iPod and I am sure it will make her commute more enjoyable,' said Tony Reed, Executive Director of the British Dental Trade Association (BDTA). 